
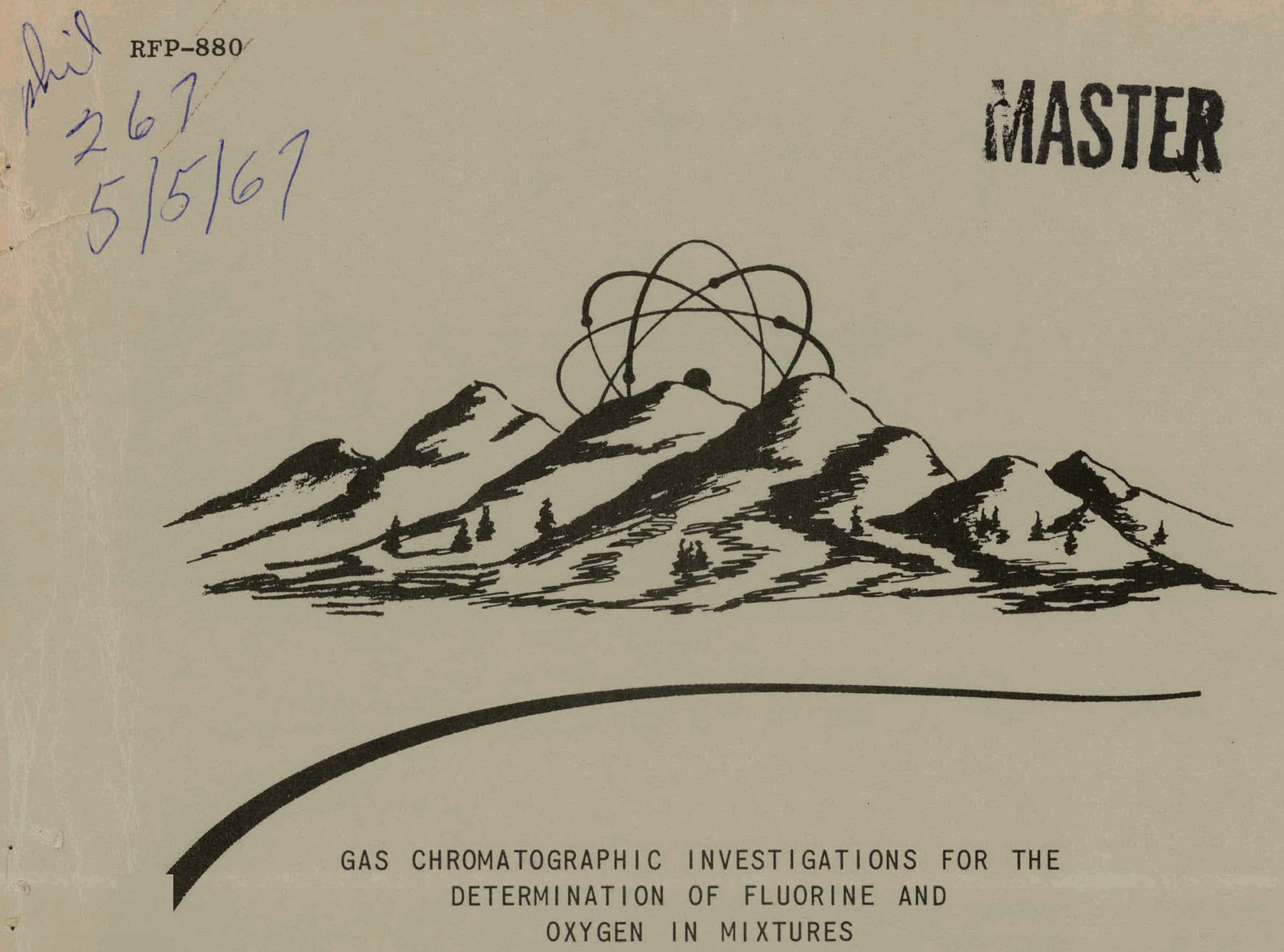

by

Robert P. DeGrazio

Robert G. Auge
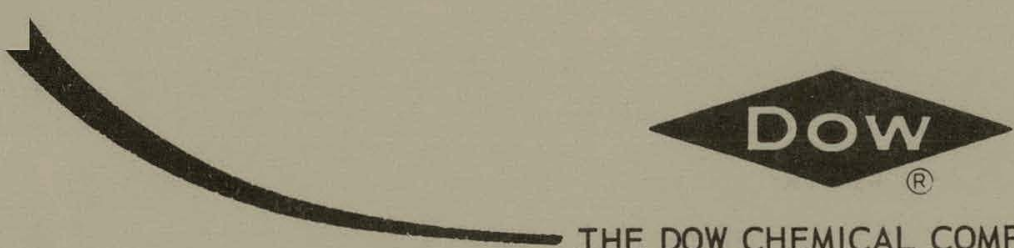

THE DOW CHEMICAL COMPANY

ROCKY FLATS DIVISION

P. O. BOX 888

GOLDEN, COLORADO 80401

U.S. ATOMIC ENERGY COMMISSION

CONTRACT AT(29-1)-1106 


\section{DISCLAIMER}

This report was prepared as an account of work sponsored by an agency of the United States Government. Neither the United States Government nor any agency Thereof, nor any of their employees, makes any warranty, express or implied, or assumes any legal liability or responsibility for the accuracy, completeness, or usefulness of any information, apparatus, product, or process disclosed, or represents that its use would not infringe privately owned rights. Reference herein to any specific commercial product, process, or service by trade name, trademark, manufacturer, or otherwise does not necessarily constitute or imply its endorsement, recommendation, or favoring by the United States Government or any agency thereof. The views and opinions of authors expressed herein do not necessarily state or reflect those of the United States Government or any agency thereof. 


\section{DISCLAIMER}

Portions of this document may be illegible in electronic image products. Images are produced from the best available original document. 


\section{LEGAL NOTICE}

This report was prepared as an account of Government sponsored work. Neither the United States, nor the Commission, nor any person acting on behalf of the Commission:

A. Makes any warranty or representation, expressed or implied, with respect to the accuracy, completeness, or usefulness of the information contained in this report, or that the use of any information, apparatus, method, or process disclosed in this report may not infringe privately owned rights; or

B. Assumes any liabilities with respect to the use of, or for damages resulting from the use of any information, apparatus, method, or process disclosed in this report.

As used in the above, "person acting on behalf of the Commission" includes any employee or contractor of the Commission, or employee of such contractor, to the extent that such employee or contractor of the Commission, or employee of such contractor prepares, disseminatęs, or provides access to, any information pursuant to his employment or contract with the Commission, or his employment with such contractor.

Printed in USA. Price $\$ 3$ Available from the Clearinghouse for Federal

Scientific and Technical Information, National Bureau of Standards

U. S. Department of Commerce, Springfield, Virginia. 22151 


\title{
GAS CHROMATOGRAPHIC INVESTIGATIONS FOR THE DETERMINATION OF FLUORINE AND OXYGEN IN MIXTURES
}

by

\author{
Robert P. DeGrazio
}

Robert G. Auge

\section{LEGAL NOTICE}

This report was prepared as an account of Government sponsored work. Nelther une United States, nor the Commisston, nor any person acting on behalf of the Commisston:

A. Makcs any warranty or representation, expreseed or implied, with respect to the accuA. Mre of any information, apparatus, method, or process disclosed in this repart may not Infringe privalely ownor rightis: or

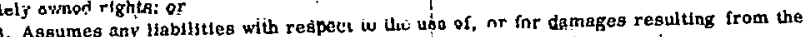

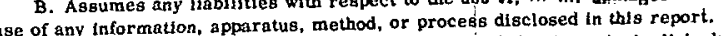

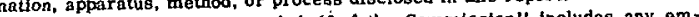
As used in the above, "person acting on behal or the commen ployee or contractor of the Commisston, or amployee or such contractor, to the exty that such employee or contractor of the Commission. or employee of such contractor prepares, disseminates, or provides access to, any information pursuant w its employment or contrect with the Commission, or his employment with such contractor.

$$
\text { …… }
$$

THE DOW CHEMICAL COMPANY

ROCKY FLATS DIVISION

P. O. BOX 888

GOLDEN, COLORADO 80401

U. S. ATOMIC ENERGY COMMISSION

CONTRACT AT(29-1)-1106 
RFP -880

ii 


\section{CONTENTS}

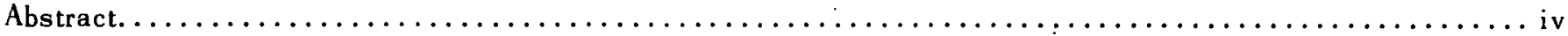

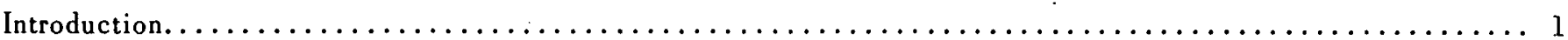

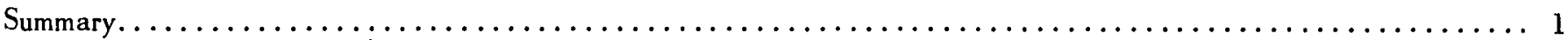

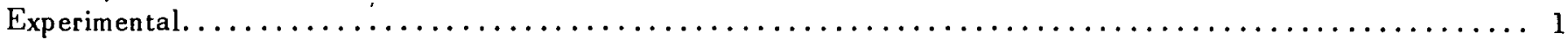

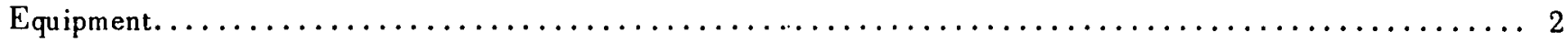

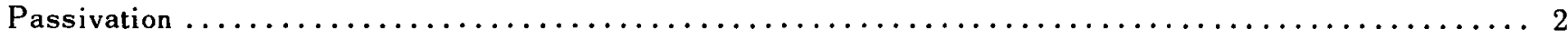

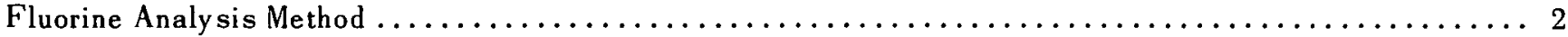

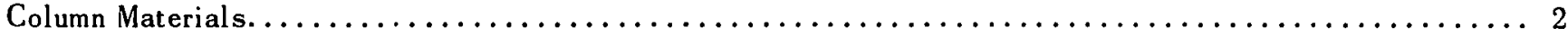

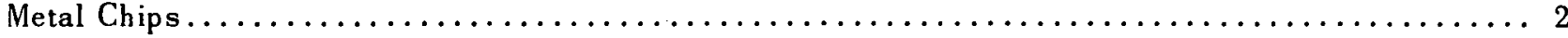

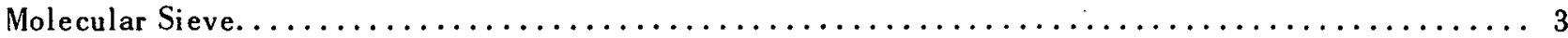

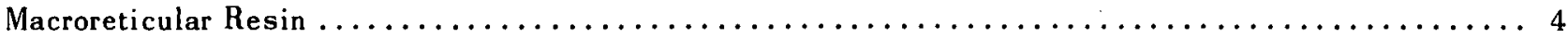

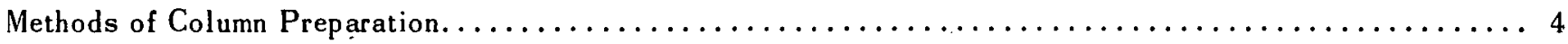

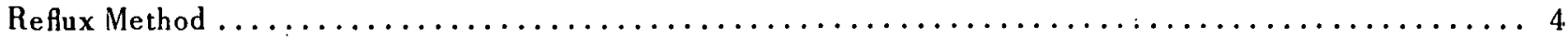

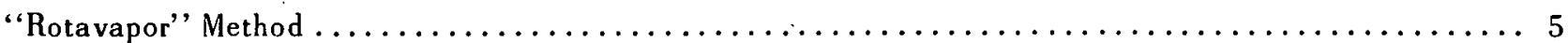

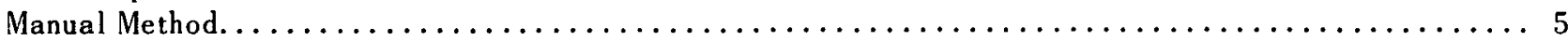

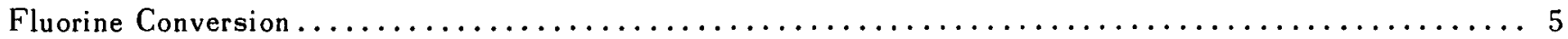

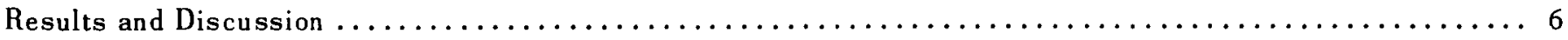

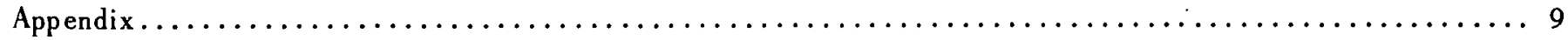




\begin{abstract}
This report describes various methods investigated for the determination of fluorine and oxygen in gas mixtures by gas chromatographic techniques. The technique found to be successful involves the quantitative conversion of fluorine to chlorine by the reaction with sodium chloride and the subsequent separation and detection of chlorine and oxygen.
\end{abstract}




\section{IN'IROIMUC:"IION}

A program has been initiated for the recovery of plutonium from various types of plutonium scrap using a fluoride volatility process. ${ }^{(1)}$ In this process, the plutonium in the scrap material is converted to plutonium hexafluoride. The plutonium hexafuoride is then reduced to plutonium tetrafluoride by thermal decomposition or by using calcium metal. The basic equations representing this process are shown below:

$$
\begin{gathered}
\mathrm{PuO}_{2}+\text { excess } \mathrm{F}_{2} \rightarrow \mathrm{PuF}_{6}+\mathrm{F}_{2}+\mathrm{O}_{2} \\
\mathrm{PuF}_{6}+\mathrm{Ca} \rightarrow \mathrm{PuF}_{4}+\mathrm{CaF}_{2}
\end{gathered}
$$

The amount of fluorine present after fluorination will be indicative of the efficiency of the conversion. Recy* cling of the excess fluorine will be required.

To determine the completeness of fluorination and the amount of oxygen in the recycle fluorine, an analytical method is required for the determination of fluorine in the presence of oxygen. A literature survey indic ated that the determination of fluorine by a gas chromatographic method is feasible. ${ }^{(2-8)}$ However, no methods have been reported for the analysis of fluorine in the presence of oxygen. Analyses by gas chromatographic methods are simple and economical.

(1) Moseley, J. D., Thermal Decomposition of Fluoride Volatility Process Gas Mixtures, The Dow Chemical Company, Rocky Flats Division, Golden, Colorado (A report of experimental work performed at Argonne National Laboratory, Chicago, Illinois).

(2) Ellis, F., Forrest, C. W., and Allen, P. L., "The Quantitative Analysis of Mixtures of Corrosive Halogen Gases by Gas-Liquid Chromatography," Anal. Chim. Acta, 22, 27-33 (1960).

(3) Iveson, G., The Application of Gas-Liquid Chromatography to the Analysis of Corrosive Gases. Part 1: Development of Apparatus and Techniques for the Separation of Mixtures of Chlorine Trifluoride, Hydrogen Fluoride, and Uranium Hexafluoride, Capenhurst, England, United Kingdom Atomic Energy Authority Production Group, Technical Department, 1961, PG Report 82.

(4) Iveson, G., and Hamlin, A. G., The Application of Gas. Liquid Chromatography to the Analysis of Corrosive Gases. Part 2: The Design of In-Line Chromatographs, Capenhurst, England, United Kingdom Atomic Energy Authority Production Group, Technical Department, 1962, PG Report 354.

(5) Hamlin, A. G., Iveson, G., and Phillips, T. R., "Analysis of Volatile Inorganic Fluorides by Gas Liquid Chromatography," Anal. Chem., 13, 2037-44 (1963).

(6) Ellis, J. F., and Iveson, G., "The Application of GasLiquid Chromatography to the Analysis of Volatile Halogens and Interhalogen Compounds," Gas Chromatography 1958, D. H. Desty, ed., New York, Academic Press, 1958, pp 300-9.

(7) Phillips, T. R., and Owens, D. R., "The Gas Chromatographic Analysis of Inorganic Halogen Compounds on Capillary Compounds," Gas Chromatography 1960, R. P. W. Scott, ed., Washington, Butterworths, 1960, pp 308-20.

(8) Iveson, G., and Hamlin, A. G., "A Gas Chromatographic Apparatus for In-Line Analysis of Corrosive Inorganic Gases," Gas Chromatography 1958, D. H. Desty, ed., New York, Academic Press, 1958, pp 33.-43.

\section{SUMMARY}

Recovery of plutonium from waste materials by a flumride volatility process is being investigated. Plutonium scrap materials are converted to plutonium hexitfluoride. The plutonium hexafluoride is then reduced to plutonium tetrafuoride and finally to metal. In this procedure fuorine and oxygen are present and an analysis needs to be determined for process evaluation and control.

Several approaches for an analytical method of analysis for fluorine and oxygen using gas chromatographic techniques were investigated. Development of instrumentation was not attempted because suitable in-line instruments have been developed by others. ${ }^{(9)}$ The system that was designed and constructed to mix and introduce the gas is unique. Various types of column materials were investigated for a direct separation of fluorine and oxygen. These columns were not successful. However, two indirect methods of analysis were successful.

Separating the mixture can be accomplished by the complete adsorption of fluorine on macroreticular resin. Oxygen is not retained on the resin and consequently will be eluted through the chromatographic resin column and recorded. This method can be used for a "batch" type analysis but is not suitable for an in-line procedure which is desired. Continuous flow through the resin will cause the macroreticular resin to discolor and evolve undesirable volatiles.

The known method of converting fluorine to chlorine by sodium chloride was investigated for possible integration into the fluoride volatility system. It is possible to release an amount of chlorine equivalent to the fluorine in the fluorine-oxygen mixture by reacting the fluorine with sodium chloride. In this investigation the reaction was done in a smaller column and at a much lower temperature than was used by other investigators. Data obtained show that this method of fuorine determination is simple and reliable.

\section{EXPERIMENTAL}

Because of the high reactivity of fluorine gas to many materials, it is necessary to work with materials that are inert to fuorine such as Teflon resin, nickel, Kel-F oils and moulding powder and the Halocarbon

(9) Williamson, E. L., Johnson, C. M., Mayo, T. J., and Rossmassler, W. R., A Chromatograph for the Analysis of Highly Reactive and Corrosive Compounds, AEC, July 8, 1965, KY-485. 
oils. (10-11) Details of the types of equipment and materials are discussed in the Appendix.

\section{EQUIPMENT}

All experimental studies were carried out on a Beckman GC-2 gas chromatograph with a Honeywell Brown Model 143 recorder. The detector of the chromatograph was specially equipped with nickel flaments. The tungsten filaments normally used would soon burn in a fluorine atmosphere. Use of nickel filaments resulted in a loss of sensitivity. This was not serious, however, because detection of low concentrations of fluorine and oxygen was not required. The "plumbing" of the chromatograph was also modified so that a more-linear base-line could be obtained.

The Matheson Company Model 940-F valves used to meter fuorine gave satisfactory service primarily because they were exposed to only small amounts of fluorine. One of the valves became corroded and began to leak. The film coating of Teflon on the valve had cracked, exposing the brass valve shaft to fluorine.

\section{PASSIVATION}

All exposed parts were passivated prior to introducing fluorine into the system. The procedure used for passivation follows: Each part to be pasaivated was thoroughly washed with a solution of Tide detergent and water. The parts were then washed with acetone and Freon TF liquid and then air dried. During this cleaning procedure, the parts were handled with surgeons' gloves to eliminate the possibility of organic contamination.

After assembly, the system was pressurized with helium and then it was leak checked. Fluorine diluted with helium was then introduced into the system. The concentration of the fluorine was gradually increased from 5 to 100 percent. The $F_{2}-H e$ mixture was allowed to remain in the system for one hour at each concentration level.

To insure complete passivation, pure fluorine remained in the system for 4 hours. During the passivation procedure, a check for leaks was performed by using potassium iodide-starch paper which is sensitive to $0.3 \mathrm{ppm}$ of fluorine.

(10) Kirkland, J. J., "Fluorine-Containing Polymers as Solid Supports in Gas Chromatograpby," Anal. Chem., 35, 2003-9 (.963).

(11) Ottenstein, D. M., "Column Support Materials for Use in Gas Chromatography." Journal of Gas Chromatography, 1, No. 4, 20-1 (1963).

\section{FLUORINE ANALYSIS METHOD}

After the system was passivated and leak-checked, standard mixtures of $\mathrm{F}_{2}$ and $\mathrm{O}_{2}$ were introduced. Fluorine gas is introduced into the manifold of the gas mixing system, shown in Figure 1, through the HF trap. The amount of gas introduced is measured by the pressure gage of the manifold. Other gases such as oxygen, chlorine, chlorine trifluoride and helium are introduced and measured in a similar manner. The calibrated sample loop is flled with the gas in the manifold and then is passed to the chromatographic columns. The flowmeter is calibrated to measure the flow rate of the carrier gas through the columns. The $\mathrm{NaCl}$ converters in the system were used to convert waste fluorine gas to chlorine for easier disposal. The molecular sieve traps were used for water removal from the gases.

Columns containing various chloro-fluorocarbon materials were evaluated using varying chromatographic operating conditions. The Freon gases, designated $12\left(\mathrm{CCl}_{2} \mathrm{~F}_{2}\right), 13\left(\mathrm{CClF}_{3}\right)$, and $22\left(\mathrm{CHClF}_{3}\right)$, were substituted for fluorine in the initial evaluation of the columns. Halocarbon oils, designated No. $11 / 14 \mathrm{E}$ and No. $13 / 11 \mathrm{E},{ }^{(12)}$ on a support of Teflon 6 resin were used for column materials.

The column parameters investigated were: methods of preparation, methods of column packing, length of column, and type of column material. The combination that produced the optimum separation of mixtures of Freon gases and oxygen was used in the investigations for fluorine-oxygen separation.

Halocarbon oil No. 13/21E on a support of Teflon 6 resin gave an excellent separation for mixtures of Freon gases and oxygen. A typical chromatogram of the separation using this column is shown in Figure 2.

Although excellent separation of the. Freon gases and oxygen was obtained, fluorine and oxygen were not separated but were eluted as a composite peak.

Because of the inability of this type of column material to separate fluorine and oxygen, other column materials and methods of preparation were invegtigated. The results obtained from each are discussed.

\section{COLUMN MATERIALS}

\section{Metal Chips}

A column material that has a large surface area would be capable of sepurating components present in a

(12) Halocarbon Uils, Greases and Waxes, Technical literature by the Halocarbon Product Corporation, 82 Burlews Court, Hackensack, New Jersey, June 1957. 


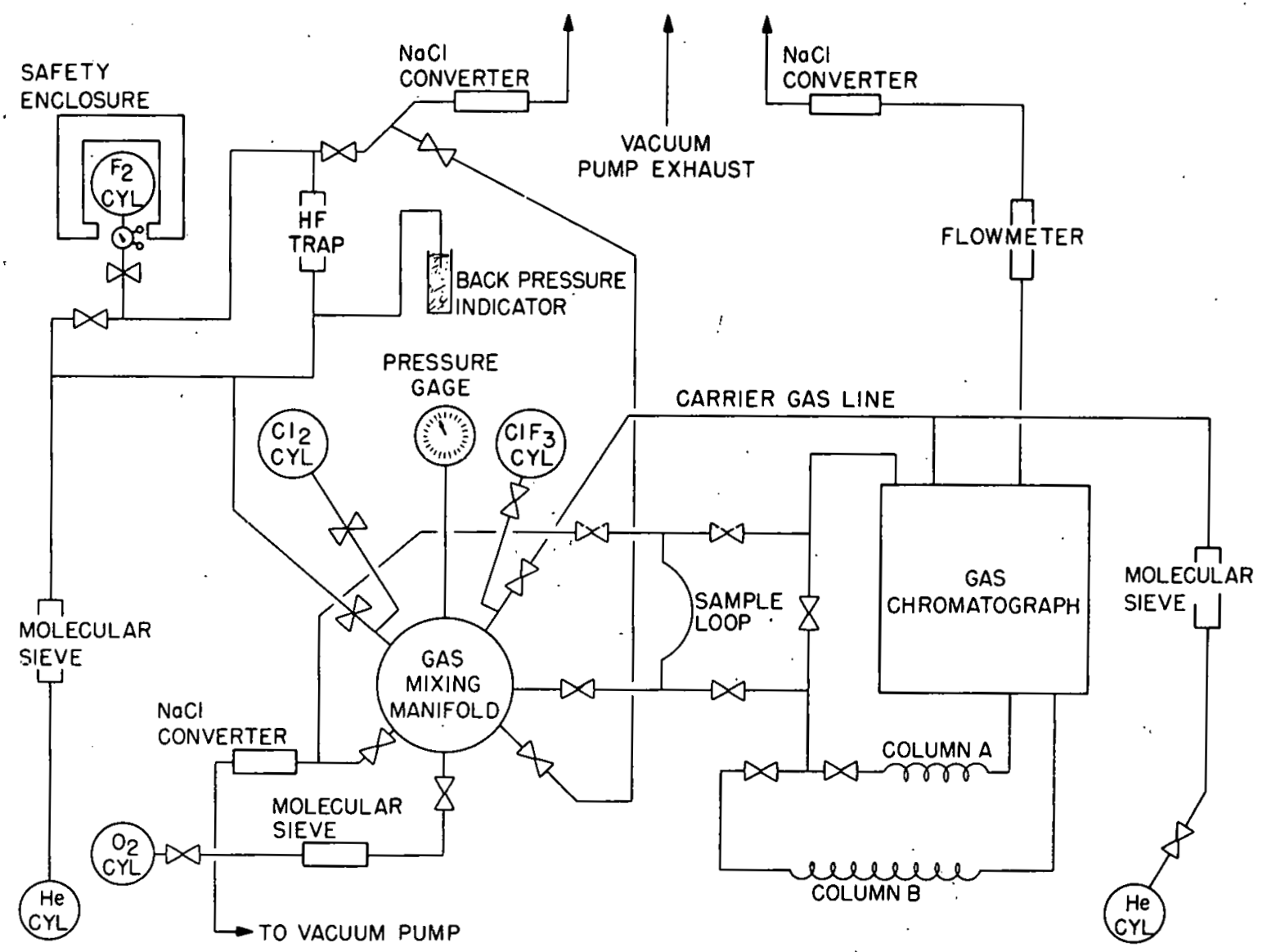

Figure I. SCHEMATIC OF FLUORINE-OXYGEN ANALYZING SYSTEM.

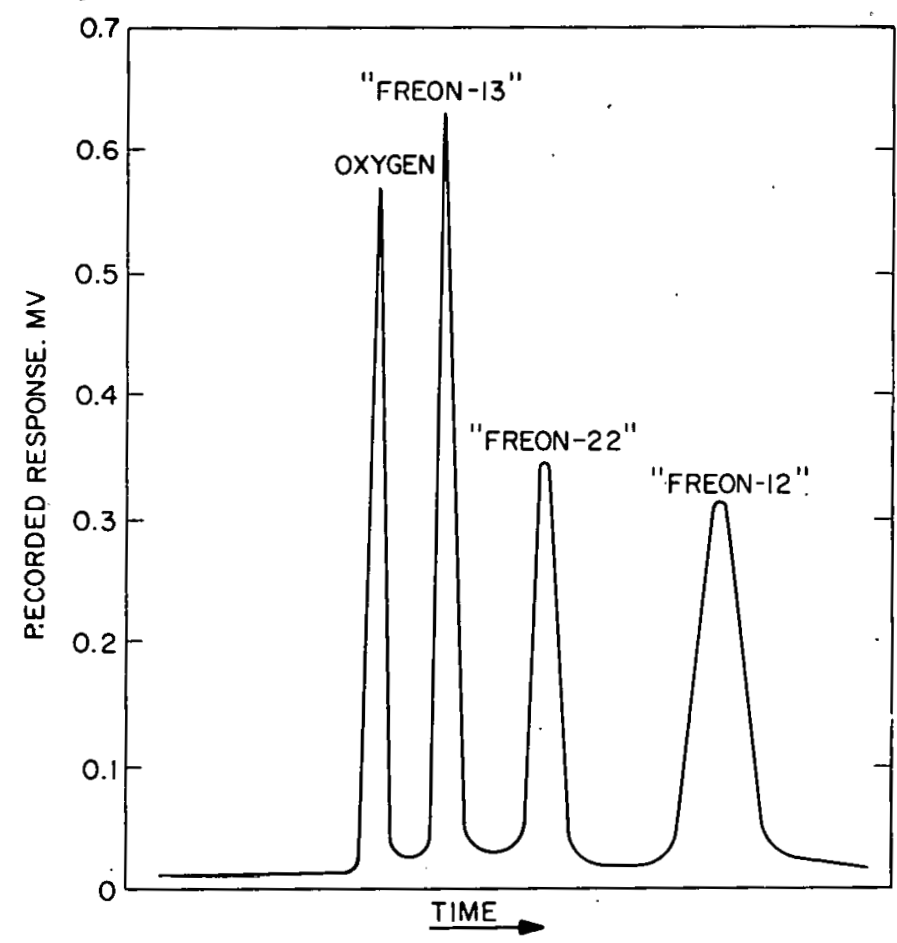

Figure 2. SEPARATION OF OXYGEN AND "FREON" GASES ON A COLUMN OF HALOCARBON OIL AND TEFLON 6 RESIN. gaseous mixture. (13) On this basis, columns packed with metal chips were investigated as a separating media. Nickel chips would have been preferred, but they were unavailable, so iron and tin chips were used as substitutes. Two 6-foot by $1 / 4$-inch OD columns were filled with the chips; one with tin and the other with iron. Fluorine and oxygen were introduced in the columns; however, separation of $\mathrm{F}_{2}$ and $\mathrm{O}_{2}$ did not occur.

Molecular Sieve

Molecular sieve $5 \mathrm{~A}$ was investigated as a possible column material because of its known capabilities in separating a wide variety of other gases. If the molecular sieve did not react with fluorine at room temperature, separation was a possibility because molecular sieve has a tendency to react in oxygen up to about $100^{\circ} \mathrm{C} .(14)$

Unexpectedly, however, oxygen was eluted from the column and fuorine was retained. Also, an unknown

(13) Private communication with Dr. P. Urone, Chemistry Department, University of Colorado, Boulder, Colorado, March 4, 1963.

(14) Littlewood, A. B., Gas Chromatography, Principles, Techniques, and Applications, New York and London, Academic Press, 1962, p 374. 
compound was eluted (not $F_{2}$ ) that had the same retention time as fluorine. The molecular sieve also burned in high concentrations of fluorine. For these reasons, further investigations with molecular sieves were discontinued.

\section{Macroreticular Resin}

Macroreticular resins have a rigid, macroporous structure which does not shrink on drying and is insoluble in acids. These properties plus the difference in the physical configurations* of the fluorine and oxygen molecules initiated an experiment where the Amberlite IRA911 macroreticular resin was investigated as a separating medium for fluorine and oxygen. Amberlite IRA911 resin is a relatively new synthetic anion exchange resin containing strong base functional groups. (15) Because of the resin structure, it was thought that separation of the two gases might be obtained. A $2 \frac{1}{2}$-foot length of $1 / 4$-inch OD nickel tube was filled with the macroreticular resin.

The resin did not burn in the presence of $80 \mathrm{v} / 0$ fluorine. However, a few of the resin beads at the entrance of the column became discolored, indicating a reaction. Several of these beads were removed from the column and observed under a stereoscopic microscope at $90 \mathrm{X}$ magnification. The beads were dark brown in color. However, there was no indication of decomposition or cracking. Also, the beads had retained their spherical form.

* Bond Lengths: $\dot{F}_{2}=1.417$ angstroms.

$$
\mathrm{O}_{2}=1.208 \text { angstroms. }
$$

(15) Macroreticular Anion Exchange Resins, a paper presented at the International Water Conference, Pittsburgh, Pennsylvania, October 1963, by Donald Downing and Kichard Hetherington of the Rohm and Haas Company.
When discoloration of the resin beads occurred, a small, unknown peak was eluted. Tests showed that this component was neither fuorine nor oxygen. The unknown component was apparently a reaction product of fluorine and resin. Fluorine was totally retained on the resin and oxygen was eluted. The complete retention of fluorine on the resin suggested a possible "indirect" method for its determination. This indirect method is described below.

A known volume of an $\mathrm{F}_{2} / \mathrm{O}_{2}$ sample mixture was split into two equal parts at Point $\mathrm{S}$ shown in Figure 3. The carrier gas flow rates through Columns $A$ and $B$ are regulated to permit the components through Column $A$ to be eluted first. The fluorine and oxygen will be eluted as a composite peak through Column $A$. In Column $B$, fluorine will be retained and oxygen will be eluted. A chromatogram of this event is shown in Figure 4. The difference in peak areas between the composite peak and oxygen peak would be equivalent to the fluorine content.

It is not advisable to use this type resin where large amounts of fluorine will be used. However, for a batch type of analysis, this method appears feasible. The method was not pursued because it was not adaptable to an in-line system.

\section{METHODS OF COLUMN PREPARATION}

\section{Reflux Method}

Kel-F 300 moulding powder was used as a column support and Halocarbon oil as a liquid phase. The moulding powder has a relatively small surface area. Due to this small surface area, a high ratio of liquid phase to support would be difficult to obtain. To overcome this

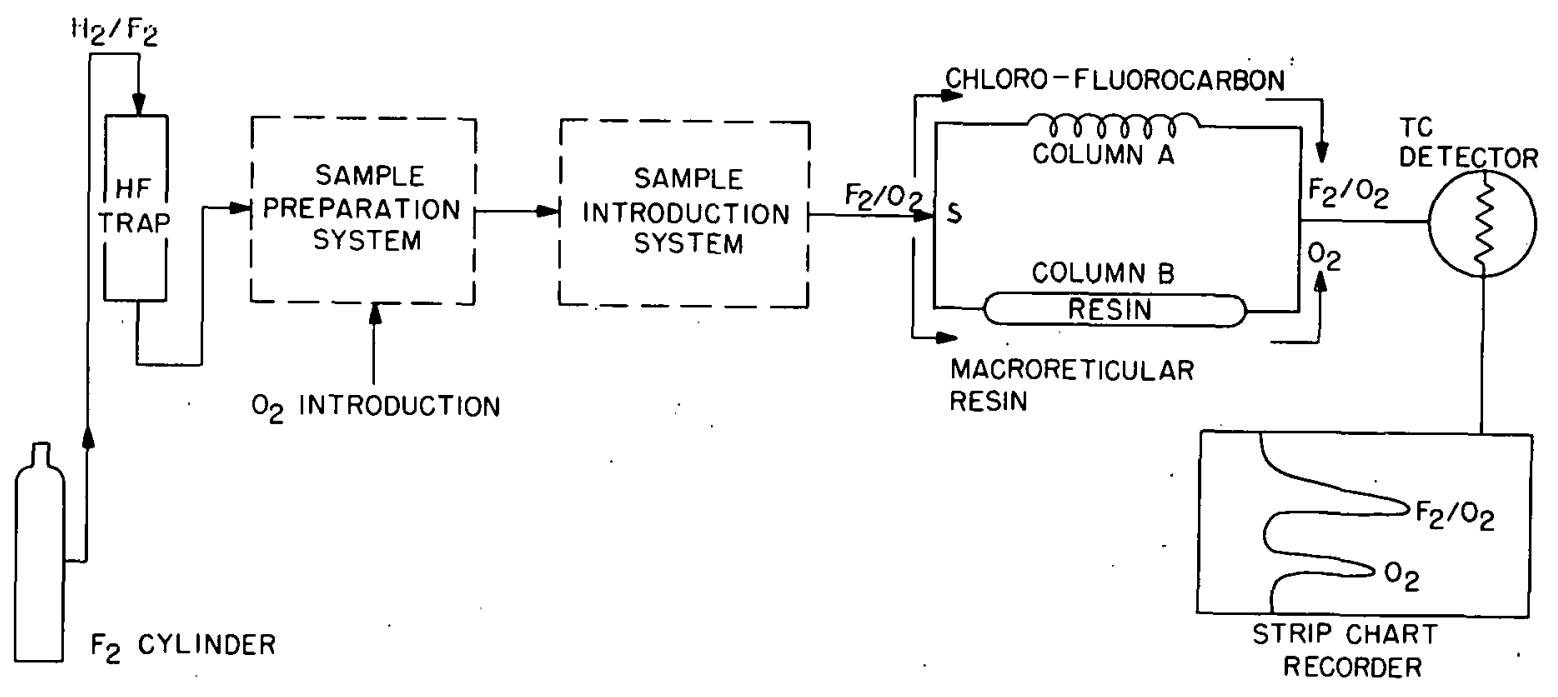

/Figure 3. SCHEMATIC OF SYSTEM USED FOR THE DETERMINATION OF FLUORINE USING A BY-DIFFERENCE METHOD. 


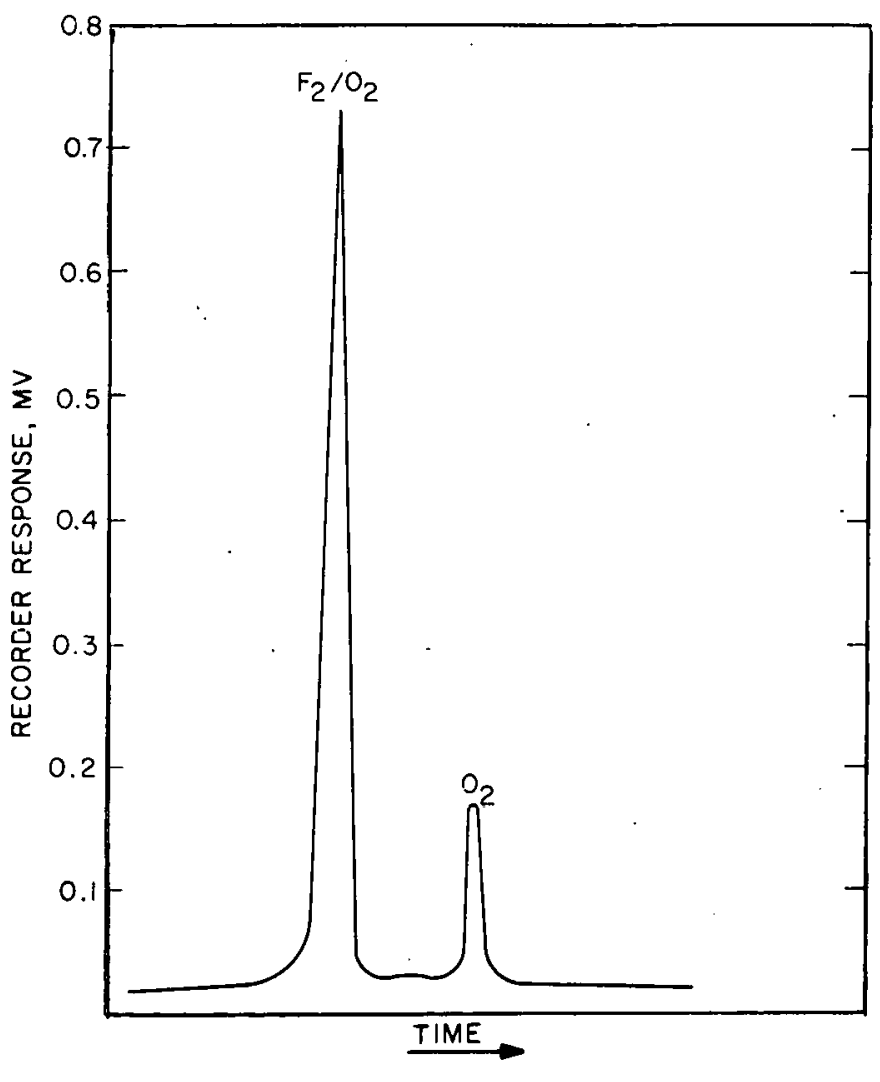

Figure 4. CHROMATOGRAM OBTAINED FROM THE SEPARATION SYSTEM SHOWN IN FIGURE 3.

condition, Lysyj and Newton ${ }^{(16)}$ have prepared what they called a Monophase-Gel (monogel) column material. The monogel was composed of 50 percent Halocarbon oil No. $13 / 21 \mathrm{E}$ and 50 percent Kel-F 300, low density, moulding powder. The monogel was prepared in the following manner: Halocarbon oil No. 13/21E was dissolved in a suspension of trichloroethylene and moulding powder. The mixture was refluxed for 15 minutes. It was then spread over a sheet of Teflon and the excess trichloroethylene was allowed to evaporate to dryness. The material (according to Lysyj and Newton) consisted of 50 percent Halocarbon oil and 50 percent Kel-F moulding powder. Lysyj and Newton have separated several fluorocarbons and also fluorine on this type of column, but not in the presence of oxygen. A 6-foot by $1 / 4$-inch OD column of Teflon packed with the monogel failed to separate mixtures of fluorine and oxygen.

(16) Lysyj, I., and Newton, P. R., "Evaluation of Gas Chromatographic Columns for the Separation of Fluorinated Materials," Anal. Chem., 35, 90-2 (1963).

\section{“Rotavapor” Method}

Halocarbon oil No. 13/21E was coated on support material of Kel-F 300 by use of the Rotavapor evaporator. The oil was dissolved in dichloromethanc and added to the support which was in the retort of the Rotavapor. Vacuum was applied to the retort and simultaneously it was heated while being rotated at a low speed during the coating process. When the process was complete, the material was removed from the retort and packed into a column. It was found that it is not possible to obtain a large percentage of liquid phase on the support by this method of preparation. Also the separation capabilities of this column for $\mathrm{F}_{2}$ and $\mathrm{O}_{2}$ were not improved over those obtained when the column material was prepared by the reflux method.

\section{Manual Method}

The column materials were placed in a beaker and a slurry was made with dichloromethane. The slurry was stirred for one minute every 10 minutes. This procedure continued for 2 hours. A coating of $-8 \mathrm{w} / \mathrm{o}$ was obtained. The material was dried and packed into a column. Again, separation of $F_{2}$ and $\mathrm{O}_{2}$ did not occur.

A special column packing procedure is required when working with support materials of Teflon and Kel-F. This type of material will form aggregates and consequently the columns will plug during packing. To prevent this, the column material is cooled to a temperature between 0 and $10^{\circ} \mathrm{C}$ with the use of liquid nitrogen. At this temperature, aggregation does not occur and the column is easily packed. Caution must be exercised to prevent losing some of the liquid phase when cooling the column material to these low temperatures.

\section{FLUORINE CONVERSION}

The inability to separate fluorine from oxygen on the gas chromatographic columns, as discussed in the preceding section, led to an investigation of an indirect method of analysis. This method consists of generating chlorine equivalent to fluorine, then separating the chlorine from oxygen using Halocarbon oils on a support of Teflon as the column material. Investigators $(9,17)$ have shown that the

(9) Williams, E. L., loc. cit., p 1.

(17) Rochefort, O., "Analysis of Corrosive Fluorine Compounds by Gas Chromatography - Control of Free Fluorine," Anal. Chim. Acta, 29, 350-7 (1960, in French). 


\section{RFP-880}

conversion of fuorine to chlorine is quantitative and follows the stoichiometric equation,

$$
2 \mathrm{NaCl}+\mathrm{F}_{2} \rightarrow \mathrm{Cl}_{2}+2 \mathrm{NaF}
$$

The gas chromatographic system was redesigned to obtain data by this indirect method for $\mathrm{F}_{2}$ analysis. A schematic of the system is shown in Figure 5. Hydrofluoric acid that may be present in $F_{2}$ is removed by an HF trap.

Various concentrations of $\mathrm{F}_{2} / \mathrm{O}_{2}$ mixtures were prepared and introduced into the $\mathrm{GC}$ column. The $\mathrm{F}_{2} / \mathrm{O}_{2}$ mixture, after leaving the mixing manifold in the Sample Introduction System, is split at a $1: 1$ ratio at Point $S$ in Figure 5. The $\mathrm{F}_{2} / \mathrm{O}_{2}$ aliquot flowing through Column 1 is eluted as a composite peak. Fluorine in the $\mathrm{F}_{2} / \mathrm{O}_{2}$ mixture is converted to chlorine by the sodium chloride column. The chlorine and oxygen in the mixture are separated by Column 2. A typical chromatogram of this event is shown in Figure 6.

\section{RESULTS AND DISCUSSION}

Calibration curves for fuorine and chlorine were prepared from commercial gases. A linear curve was obtained for fluorine in the concentration range of 8 to 100 percent by volume. The stoichiometry of the $F_{2}$ $\mathrm{NaCl}$ reaction was checked using samples containing fluorine and oxygen in helium. The same concentrations were used as in the preparation of the fluorine standard curve. These samples were passed through the conversion tube containing $\mathrm{NaCl}$ and the amount of chlorine produccd was determined. The curve prepared from

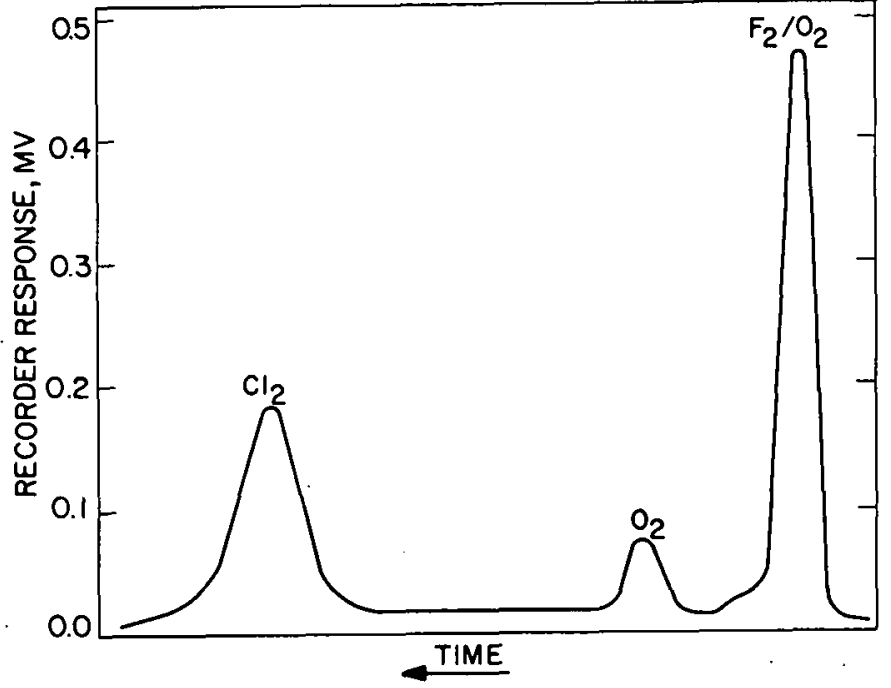

Figure 6. CHROMATOGHAM OF $\mathrm{F}_{2} / \mathrm{O}_{2}$ MIXTURE AFTER $F_{2}$ CONVERSION TO $\mathrm{Cl}_{2}$.

these results is shown in Figure 7. This indicates a 1: l ratio of fluorine added to chlorine recovered.

Table I shows the results of a series of analyses of synthetic standard mixtures of fluorine and oxygen. The results were obtained by the indirect method in which chlorine was produced by the reaction between sodium chloride and fluorine. Three $\mathrm{F}_{2} / \mathrm{O}_{2}$ mixtures at the same concentration were prepared for each series. The precision could be improved, it was fclt, if a precision splitter and a non-corrosive precision pressure gage were used in preparing the $\mathrm{F}_{2} / \mathrm{O}_{2}$ mixtures. When this work was performed, neither was available.

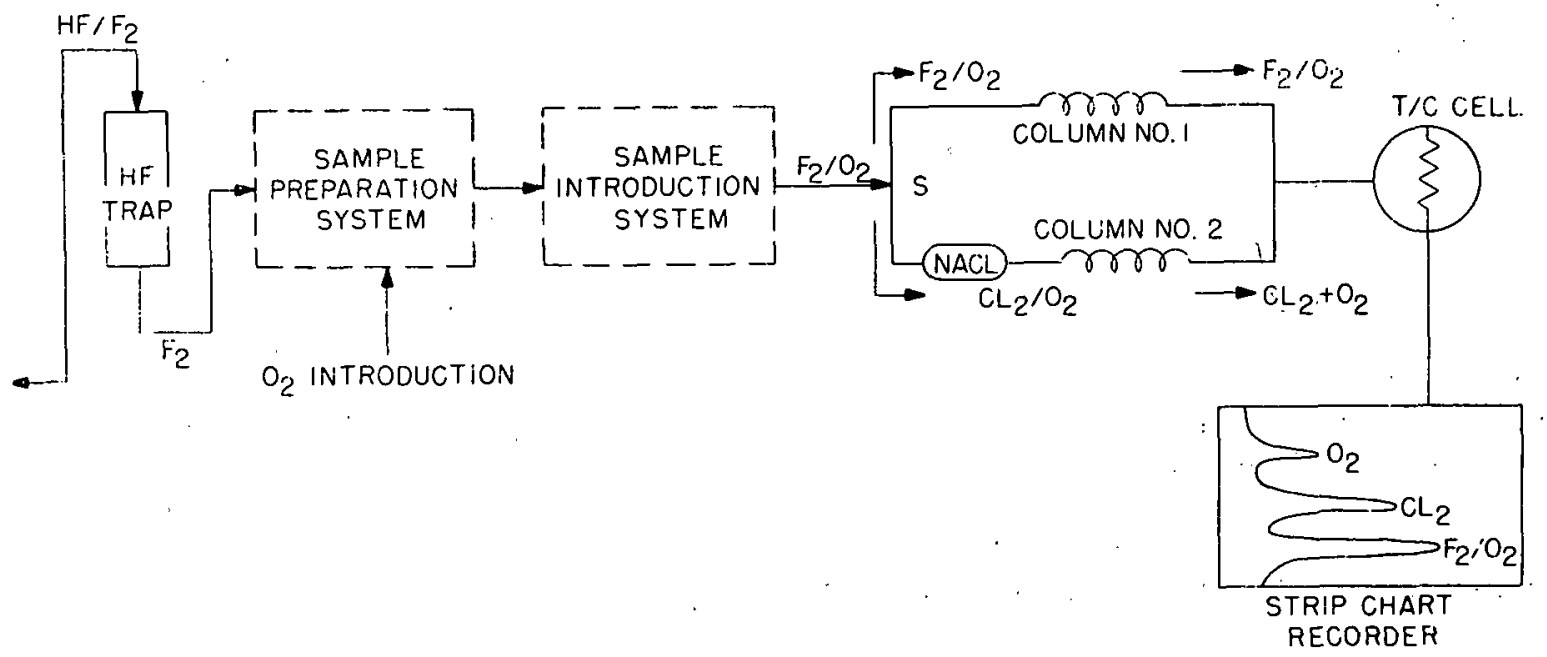

Figure 5. SCHEMATIC OF SYSTEM USEI) FOR FLUORINE-TO-CHIOHINE. CONVIIISION. 


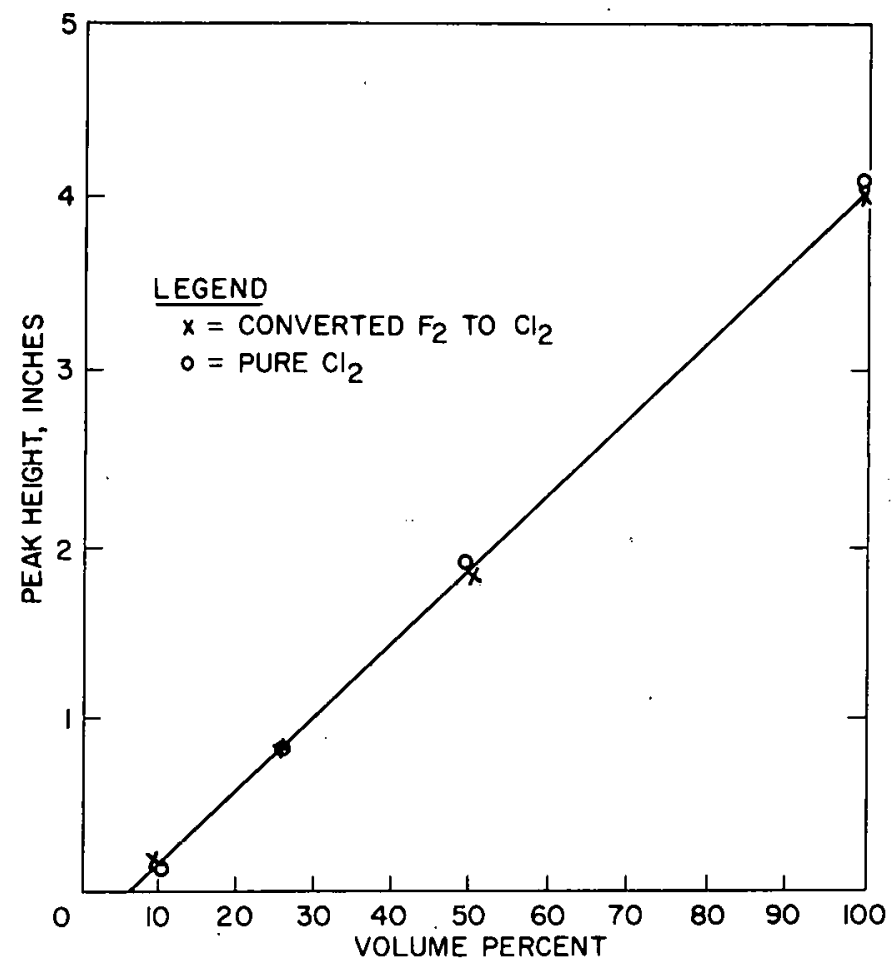

Figure 7. CALIBRATION CURVE FOR CONVERTED FLUORINE AND PURE CHLORINE.

TABLE I GAS CHROMATOGRAPHIC ANALYSIS OF FLUORINE-OXYGEN MIXTURES AT VARIOUS CONCENTRATIONS

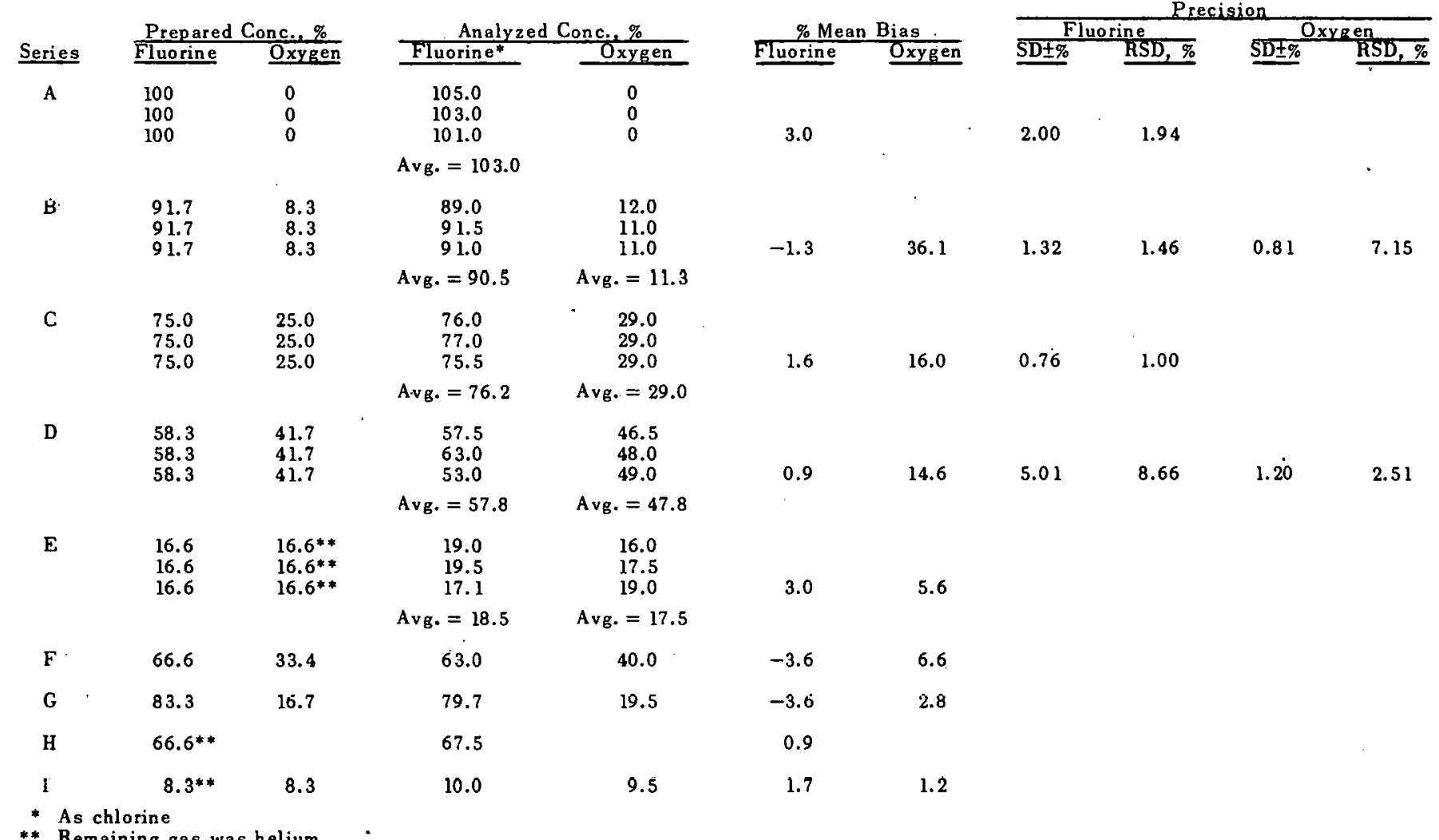


RFP-880 
This section lists the apparatus and materials for the gas chromatographic system used in the investigation.

\section{EQUIPMENT AND MATERIALS}

\section{EQUIPMENT}

\section{a. Chromatograph:}

Beckman Model GC-2, equipped with nickel thermal conductivity detector filaments. The nickel filaments were obtained from the Gow-Mac Instrument. Company, Madison, New Jersey.

\section{b. Recorder:}

The recorder was a Honeywell Brown Model 143, equipped with a standard mercury battery. The recorder had a l-mv full-scale span of 11 inches, with a response time of one second. A non-variable chart speed of 0.5 -inch per minute is standard with this recorder.

\section{c. Rotary Vacuum Evaporator:}

A Rotavapor evaporator was used to prepare several column materials. This evaporator is manufactured by the Swissco Instrument Company, Greenville, Illinois.

\section{d. Potentiometer Pyrometer:}

The Minimite pyrometer was used to meas ure column temperaturcs. It is manufactured by the Thermo Electric Company, Saddlebrook, New Jersey.

e. Test Gage:

Type 210M, 6-inch dial, 30 -inch vacuum dial range, mainufaclured by the Marsh Instrument Company, Skokie, Illinois.

f. Flowmeter:

A gas flowineter was custom constructed to handle fluorine. It consisted of a graduated glass tube to which fittings of Teflnn were attached at cither cnd. A stainless steel ball was used as the flow indicator. The inside walls of the tube were coated with a thin film of Kel-li nil for protection of the glass tube against hydrofluoric acid that may be present.

\section{g. Valves:}

Two types of valves were incorporated in the GC system. Both types were obtained from the Matheson Company, Joliet, Illinois.

1) Metering valve, instrument type, Model 940-F (made especially for fluurine service).

2) Auxiliary needle valve Model 33, made of Monel metal.

\section{h. Hydrogen Flunride Trap:}

A trap to remove hydrogen fluoride from commercial fluorine was obtained from the Mathes on Company, Joliet, Illinois. The trap consisted of a tube filled with anhydrous sodium bifuoride pellets. It was covered with a l-inch layer of asbestos, and heated electrically.

i. Vacuum Pump:

The pump was a Welch-Duo Seal mechanical pump, Model 1405, obtained from the Welch Scientific Company.

\section{j. Gas-Mixing Manifold:}

The manifold, fabricated by our design, was a circular device, 5 inches in diameter and 3.75 inches in height. It had seven ports. The manifold was made from Monel metal.

\section{k. Tubing:}

The tubing (RM No. 875 Ex), made of Teflon, was purchased from Raybestos-Manhattan Company, Denver, Colorado. It had the following specifications: nominal size $3 / 16^{3}$-inch ID with a wall thickness of 0.04 inch.

\section{Nickel Tubing:}

Twu lypes of tubing were obtained from the Metal Goods Corporation, Denver, Colorado. (The two kinds used had the following specifications: $1 / 4$-inch 
OD with 0.035 -inch wall thickness and $1 / 3$-inch OD with 0.032 -inch wall thickness.

m. Fluorine Cylinder Enclosure:

A safety enclosure to contain a No. 3 fuorine cylinder was fabricated from Transite asbestos-cement. A $1 / 8$-inch stainless steel plate covered the Transite for extra protection.

\section{MATERIALS - LIQUID PHASES}

\section{a. Kel-F Oils:}

Kel-F Oil No. 10, Kel-F Oil No. 40 and Kel-F Wax No. 210 were investigated for use as liquid phases. They are manufactured by The Minnesota Mining and Manufacturing Company, St. Paul, Minnesota.

b. Halocarhon Oils:

Halocarbon Oil No. 13/11E, Halocarbon Oil No. $11 / 14 \mathrm{E}$ and Halocarbon Oil No. 208 were investigated for use as liquid phases. Halocarbon oils are low molecular weight polymers of chlorotrifluoroethylene, manufactured by The Halocarbon Product Corporation, Hackensack, New Jersey.

\section{COLUMN SUPPORTS}

a. 'Teflon 6 Resin:

Teflon 6 polymerized tetrafluoroethylene resin is manufactured in a number of different forms under the trademark Teflon by the DuPont Company, Wilmington, Delaware.

\section{h. Halopart F Reșin:}

Haloport $F$ is the designation used by the $F+M$ Scientific Corporation, State College, Pennsylvania for a resin similar to the 'I'eflun resill. The surfác area of Haloport $F$ is $7.8 \mathrm{~m}^{2} /$ gram compared to the surface area of $11.67 \mathrm{~m}^{2} /$ gram of Teflon 6 .

c. Kel-F Moulding Powder:

Type $6051 \mathrm{Kel}-\mathrm{F}$ granular moulding powder is a chloro-fluorocarbon. The granules are hard and do not tend to aggregate as easily as Teflon 6 resin. It can be handled in a manner similar to diatomaceous earth supports during column preparations.

\section{GASES}

a. Fluorine:

A No. 3 cylinder, containing $1 / 2$ pound fuorine at a pressure of 300 psig, purity 98.0 percent, was obtained from the Matheson Company, Joliet, Illinois.

\section{b. Chlorine Trifluoride:}

Lecture bottle size, purity 99.965 percent, obtained from the Matheson Company, Juliet, Illinuis.

c. Frèòn Gases:

Size No. 2 cylinders of Freon gases designated 12, 13 , and 22 , each containing 25 pounds of gas, purity 99.9 percent, were obtained from the DuPont Company, Antioch, California.

\section{MISCELLANEOUS COLUMN MATERIALS}

\section{a. Macroreticular Resin:}

The Amberlite Type IRA-911 synthetic ion exchange rcsin is manufactured by the Rnhm and Haas Company, Philadolphia, Pennsylvania.

b. Molecular Sieve $5 \mathrm{~A}$ :

The material used was 60 to 80 mesh; manufactured by the Linde Company, Hermosa Beach, California.

c. Iron Chips:

Mincu Plint-Iron irnn chipe, manufactured hy the Midwest Instrument Company, Milwaukee, Wisconsin.

\section{d. Tin Chips:}

Leco tin metal accelerator, Part No. 501-76, manufactured by the Laboratory Equipment Company, St. Joseph, Michigan. 